\title{
Patella resurfacing during total knee arthroplasty is cost-effective and has lower re-operation rates compared to non- resurfacing
}

Thomas Parsons ${ }^{1,2}$, Talal Al-Jabri ${ }^{3}$, Nick D. Clement ${ }^{1,4}$, Nicola Maffulli, ${ }^{5,6,7}$ and Deiary F. Kader ${ }^{1,8^{*}}$ (D)

\begin{abstract}
Background: The decision to resurface the patella as part of total knee arthroplasty may be influenced by the surgeon's preference, education, training, tradition and geographic location. Advocates for non-resurfacing or selectively resurfacing may claim no difference in patient reported outcomes, and that resurfacing is associated with increased risks such as extensor mechanism injury or malalignment, problems with the design of the patella component and technical issues intraoperatively.
\end{abstract}

Aims: To critically examine factors that should be considered in addition to patient reported outcomes in the decision process of resurfacing or non-resurfacing of the patella in total knee arthroplasty.

Method: A comprehensive literature search was conducted to identify factors that may influence decision making in addition to knee specific patient reported outcome measures such as surgical risks, patient quality of life, procedure cost, re-operation rate, implant design, surgeons learning curve and the fate of remaining cartilage in native patellae.

Results: Patient-reported outcomes are equivocal for resurfacing and non-resurfacing. Critical analysis of the available literature suggests that the complications of resurfacing the patella are historic, which is now lower with improved implant design and surgical technique. Routine resurfacing was cost-effective in the long term (potential saving $£ 104$ per case) and has lower rates of revision (absolute risk reduction 4\%). Finally, surgical judgment in selective resurfacing was prone to errors.

Conclusion: Patella resurfacing and non-resurfacing had similar patient-reported outcomes. However, patella resurfacing was cost-effective and was associated with a lower rate of re-operation compared to non-resurfacing.

Keywords: Arthroplasty, Patella, Knee replacement, Resurfacing

\footnotetext{
* Correspondence: deiary.kader@gmail.com

'South West London Elective Orthopaedic Centre, Denbies Wing, Epsom

General Hospital, Surrey KT18 7EG, UK

${ }^{8}$ University of Kurdistan Hewler, Erbil, Iraq

Full list of author information is available at the end of the article
}

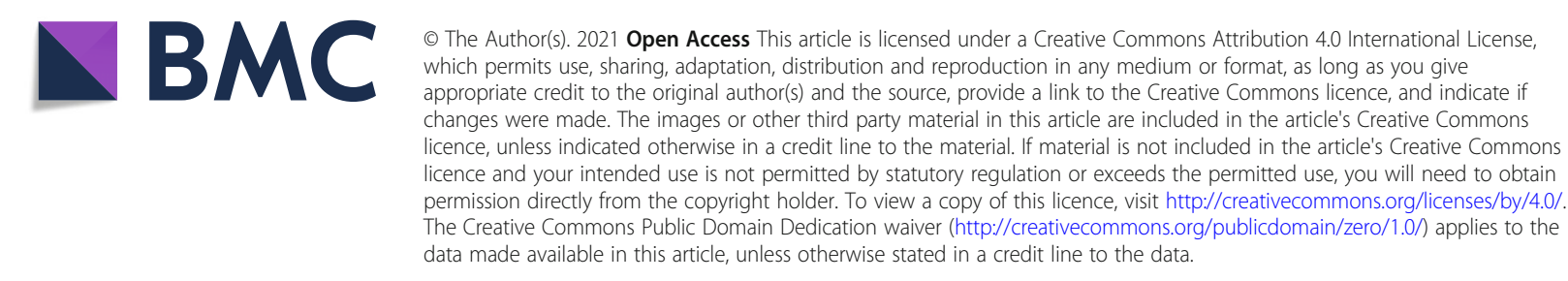




\section{Background}

The practice of patella resurfacing as part of total knee arthroplasty (TKA) remains heterogenous, with rates of primary patella resurfacing (PPR) ranging from $4 \%$ in Norway to $90.6 \%$ in the United States of America (AJRR 2018 Annual Report) [1]. The Australian Registry has shown an increase in PPR, raising from $41.5 \%$ in 2005 to $66.6 \%$ in 2017. In contrast, the rate of PPR in Sweden has continued to decrease since the mid 1980's, and in 2017 was performed in only $2.6 \%$ of TKA procedures. According to the 17th Annual Report of the United Kingdom (UK) National Joint Registry (NJR), just over one third of all TKAs registered underwent patella resurfacing [2].

Knee specific patient-reported outcome measures (PROMs) naturally assume priority when assessing whether PPR should be undertaken [3]. However, it is essential to consider other factors such as re-operation rate, patient quality of life, cost-effectiveness, influence of implant design, surgical risks, surgeons' learning curve and the fate of the remaining patella articular cartilage when not resurfaced.

The current review examined factors that surgeons may want to take into consideration include the following:

1. PROMs of PPR verses primary patella nonresurfacing (PPNR)

2. Re-operation rate and outcomes of secondary patella resurfacing

3. Patient quality of life lost and inconvenience

4. Intra-operative time spent at PPR versus readmission for secondary patella resurfacing (SPR)

5. The costs of patella resurfacing

6. Influence of implant design on outcomes

7. Surgical risks of primary patella resurfacing (patella fracture, osteonecrosis, aseptic loosening, instability, under or overstuffing, patella clunk syndrome and rupture of the extensor mechanism)

8. The fate of non-resurfaced patellae;

a. Cellular changes of the articular cartilage of the patella when everted during surgery

b. Interaction of metal on cartilage for retained patellae

\section{Methodology}

A review of the literature with a search strategy was undertaken to identify relevant articles in relation to patella resurfacing in TKA. This included a search on MEDLINE and Google Scholar from January 2010 to November 2020. Search terms included ('total knee arthroplasty' [All fields] OR 'knee arthroplasty' [MeSH terms] with all entry terms and 'patella'[All fields]) OR ('resurfacing' [MeSH terms], OR non-resurfacing' [MeSH terms]). Journals in all languages were included without any limitations in the search strategy. Abstracts were screened for relevance. Exclusion criteria included letters, editorials and studies identified as being poorly designed and of a low level of evidence. References of selected fulltext articles were screened for the inclusion of additional articles. The selected articles were critically appraised by the authors and arguments for and against resurfacing were reviewed.

\section{Results \\ PROMs of PPR vs PPNR}

Multiple recent randomised controlled trials (RCTs) and meta-analyses demonstrate comparable clinical outcomes of TKA with and without patella resurfacing [4-9]. The most recent meta-analysis of 20 randomised control trials (RCTs) found that both the knee and functional components of the Knee Society Score (KSS) were statistically significantly, although not clinically significantly, better in those undergoing PPR in additional to a lower reoperation rate for any reason and re-operation for anterior knee pain (AKP) [10]. However, all other outcomes, including AKP, re-operation for non-patellofemoral complications, patient satisfaction, Oxford Knee Score, Knee Injury and Osteoarthritis Outcome Score and range of motion, showed no significant difference.

The only randomised-control trial (RCT) comparing PPR, PPNR and selective patella resurfacing showed significantly higher (better) PROMs for the PPR and selective resurfacing groups compared with the PPNR group at 5 years [11]. Within the selective patella resurfacing group, those who underwent resurfacing had higher PROMs (significance not mentioned).

The analysis of 28 studies in a review by The National Institute for Health and Care Excellence (NICE) achieved similar results, suggesting no difference in terms of PROMs, revision (excluding patella-only revision), length of stay and deep vein thrombosis at multiple follow-up points [12]. The same review also found that PPR was beneficial with respect to quality of life and stiffness in the short term and minor revision, and re-operation in the long term.

\section{Key points}

There is no evidence that PPR or PPNR has a clinically meaningful difference in knee specific patient reported outcomes.

\section{Re-operation rate and outcomes of secondary patella resurfacing}

Ultimately, surgeons may be concerned about the proportion of patients that may require further surgery after TKA (Table 1). Advocates for routine PPR quote a reduced rate of further operations. A 2012 meta-analysis demonstarted rates of patellofemoral complications after 
Table 1 Rates of re-operation for patella-femoral problems from meta-analyses

\begin{tabular}{lll}
\hline \multicolumn{2}{l}{ Rate of re-operation for patellofemoral problems } \\
\hline PPR & PPNR & Reference \\
\hline $2.3 \%$ & 6.5 & Nizard et al. 2005 [13] \\
- & $8.7 \%$ & Parvizi et al. 2005 [4] \\
$1.2 \%$ & $3 \%$ & Pilling et al. 2012 [14] \\
$0.8 \%$ & $4.8 \%$ & Johnson et al. 2012 [15] \\
$1 \%$ & $4.6 \%$ & Teel et al. 2019 [10] \\
\hline
\end{tabular}

$P P R$ primary patella resurfacing, $P P N R$ primary patella non-resurfacing

TKA with PPR versus PNRR was $5.9 \%$ and $12.6 \%$, respectively [14]. In the same analysis, re-operation for patellofemoral joint (PFJ) problems was $1.2 \%$ for the PPR group and $3 \%$ for the PPNR group. This was corroborated by a meta-analysis of 14 RCTs by Chen et al. that found absolute risk of re-operation was reduced by $4 \%$ (95\% confidence interval [CI] 2-6\%) in the PPR group [6]. Pakos et al. also demonstrated an absolute risk reduction of $4.6 \%$ of re-operation for PPR [16].

A study comparing the outcomes of 10,157 TKAs from a regional arthroplasty registry demonstrated a higher rate of patella-only revision ( $4.8 \%$ vs $0.8 \%)$ and all cause revision ( $8.2 \%$ vs $6.3 \%$ ) for PPNR and PPR respectively [15]. Progressive patellofemoral arthritis was the indication for $87 \%$ of patella-only revisions and $53 \%$ of all cause revisions in the PPNR group.

A systematic review of registry data from six countries showed disparate practice secondary to geography as previously described and showed lower re-operation rates for PPR [17].

The cumulative revision rate for all unconstrained TKAs in the UK NJR 2020 Annual Report was 4.28\% with the patella resurfaced and $5.09 \%$ without patella resurfacing at 15 years. The mean age of both groups was 70 years, and in total 435168 resurfaced patellae are registered in the NJR versus 709884 un-resurfaced patellae [2].

A 2019 meta-analysis found re-operation rates for any reason after TKA were $10.6 \%$ for PPR and $14.7 \%$ for PPNR (risk ratio 0.71 [0.59-0.84]), re-operation rate for anterior knee pain was $1.0 \%$ for PPR and $4.6 \%$ for PPNR (risk ratio 0.28 [0.17-0.45]) and re-operation for PFJ problems excluding AKP was $2.1 \%$ for PPR and $1.2 \%$ for PPNR (odds ratio 1.55, 95\% CI 0.90 to 2.67]) [10]. The number needed to treat with PPR to prevent 1 further re-operation was 25 [10].

Secondary patella resurfacing (SPR) anecdotally benefits only $50 \%$ of patients, while exposing all of the patients them to further surgical and anaesthetic risks [12]. In one of the largest reported series of SPR outcomes using the Trent and Wales Arthroplasty Register, only $44 \%$ of patients benefitted from SPR [18]. Furthermore, $13 \%$ of patients underwent further surgery on the same knee following SPR, the majority were for persistent knee pain. Parvizi et al. studied the outcomes of 39 patients following SPR: $18 \%$ had further surgery for infection, patella maltracking or revision TKA [19].

Selective patella resurfacing has the potential to achieve optimum outcomes by resurfacing those at high risk of anterior knee pain whilst reducing risk of postoperative complications associated with patella resurfacing. In practice, assessment of patient symptoms, preoperative imaging and intra-operative findings are unreliable predictors of TKA outcomes [11, 20, 21].

\section{Key points}

The re-operation rate following PPNR was $1-8.7 \%$. The outcomes are mixed and difficult to predict. Whether initial PPR in this group of patients would have prevented post-operative pain is not possible to conclude; however, they have undergone two operations, thereby exposing them to additional risk.

\section{Patient quality of life and inconvenience}

An RCT involving 1715 TKAs followed up over 10 years found that PPR was associated with non-significant increased gain is quality of life years (QALYs) (0.187; 95\% CI -0.025 to 0.399) [22]. Data from the Australian joint registry and the NJR also suggests that PPR have a relative QALY gain of 0.64 over PPNR over the patients lifetime [23].

No measure of patient inconvenience was identified in the literature, but greater inconvenience is likely to be experienced by patients after PPNR if they are at higher risk of undergoing further procedures for which they must prepare, undergo and then recover from. A study of SPR outcomes recorded the time between primary TKA and SPR at a median of 28 months (interquartile range 20-42) [24], similar to that reported by Parvizi et al. of 29 months (range 24-92) [19]. Therefore, a proportion of patients will endure approximately 2 years of dysfunction before conversion to SPR.

\section{Key points}

Available evidence suggests PPR provides an increased quality of life advantage.

\section{Intra-operative time spent at PPR vs time for SPR}

An advantage of PPNR is avoidance of an operative step with associated reduced operative time. An RCT involving 116 surgeons at 34 centres recorded an average TKA took 2 hours including anaesthetic room and operating theatre time [22]. PPR increased the average operative time by 3 minutes [22], which is clinically non-relevant. Pilling et al. found no significant difference in operative time [14]. Perhaps more importantly, such a time saving is highly unlikely to allow for an additional patient to be 
added to the operating list on that day, negating any cumulative gain of time. Furthermore, patella resurfacing does not produce a higher rate of infection [14].

\section{Key points}

There is no evidence patella resurfacing takes significantly longer intra-operatively.

\section{Economy of patella resurfacing}

The 17th annual report of the UK NJR has established that approximately 100,000 TKA are performed annually, with an estimated cost of $£ 550$ million. The NJR also identifies that only one third of surgeons resurface the patella routinely [2]. This decision has substantial monetary implications.

A recent report by NICE suggests there is likely a cost-economic benefit from routine patella resurfacing, but does not make this a formal recommendation [12].

Those surgeons in favour of resurfacing argue that anterior knee pain can develop or persist postoperatively if the patella is not resurfaced, and this can result in the need for secondary resurfacing. However, a secondary procedure often presents to family physicians and physiotherapists prior to the orthopaedic surgeon, and this accrues cross-specialty clinic appointments with further investigations and ultimately an elective admission, use of consumables, an operating theatre session and followup care all of which have financial repercussions.

Surgeons who oppose resurfacing may argue that resurfacing could prolong operative duration, would cost more (from component costs), and is not without complication. This could subsequently lead to the clinical and economic burden of revision surgery [25, 26]. Furthermore, the importance of patellofemoral joint mechanics has become more established over the last two decades, and this has led to more 'patella-friendly' femoral component designs with sided and deeper trochlear grooves. The patella-friendly TKA and the un-resurfaced patellae aim to reduce anterior knee pain and improve patellofemoral tracking. However, these modernised designs have not been successful in restoring normal morphology [27, 28].

To determine whether patella resurfacing is costeffective, a review of the current literature identified two key studies and was consistent with the 2020 NICE guidelines for patella resurfacing $[12,22,23]$. These are summarised in Table 2.

Although the results were in favour of both lower rates of secondary surgery and reduced overall total costs for resurfaced patellae in both studies, some issues are worth highlighting $[22,23]$. Firstly, Weeks et al. showed that if the secondary resurfacing rate were reduced to $<0.5 \%$ in the un-resurfaced group of patients there would be no overall difference in costs between resurfacing and not resurfacing according to a one-way sensitivity analysis [23]. Secondly, Murray et al. reported a mean QALY increase of 0.187 in resurfaced patellae with a $95 \%$ confidence interval -0.025 to $0.399 ; p=0.08$. The authors describe this as 'a non-significant trend towards improved quality of life' [22].

It is important to balance the costs of complications related to primary patella resurfacing with the costs of managing an un-resurfaced patella when establishing a monetary viewpoint. It is also vital to identify patients

Table 2 Summary of studies evaluating cost-effectiveness of patella resurfacing

\begin{tabular}{|c|c|c|c|}
\hline Study & Design and methodology & Results & Conclusion \\
\hline $\begin{array}{l}\text { Weeks } \\
\text { et al. } \\
\text { [23] }\end{array}$ & $\begin{array}{l}\text { Cost-effectiveness analysis using data from the } 2014 \\
\text { Australian joint registry and applied to the Canadian } \\
\text { market. Quality adjusted life years (QALY) were the } \\
\text { utility scores used. } \\
\text { Study duration: projected over } 14 \text { years. } \\
443,948 \text { patients extracted from the Australian NJR } \\
\text { 225,915 patients were not resurfaced and 218,033 } \\
\text { were resurfaced. }\end{array}$ & $\begin{array}{l}9240 \text { revisions in the un-resurfaced group vs } 5992 \text { re- } \\
\text { visions in resurfaced group. } \\
\text { Mean total treatment cost per patient for un- } \\
\text { resurfaced vs resurfaced patellae at } 14 \text { years: } \$ 13 \text {, } \\
296.63 \text { vs } \$ 12,917.01 \text { and lower QALY (5.37 vs 6.01) at } \\
14 \text { years in un-resurfaced group. } \\
\text { NICE's translation and interpretation to the UK } \\
\text { healthcare system: } \\
\text { Patella resurfacing results in } £ 263 \text { saving per patient } \\
\text { (2015 US dollar to Pound Stirling currency exchange } \\
\text { rates used) un-resurfaced total cost and } 0.64 \text { extra } \\
\text { QALYs [12]. }\end{array}$ & $\begin{array}{l}\text { Patella resurfacing was cost- } \\
\text { effective according to the } \\
\text { data included in the model. }\end{array}$ \\
\hline $\begin{array}{l}\text { Murray } \\
\text { et al. } \\
\text { [22] }\end{array}$ & $\begin{array}{l}\text { Cost utility analysis performed within the UK Knee } \\
\text { Arthroplasty Trial (KAT) randomised controlled trial } \\
(\mathrm{RCT}) \\
\text { Follow-up duration: } 10 \text { years } \\
\text { Un-resurfaced patella }(n=854) \\
\text { Patella resurfacing }(n=861)\end{array}$ & $\begin{array}{l}\text { Un-resurfaced group: } 2.8 \% \text { had late resurfacing in the } \\
\text { first } 5 \text { years postoperatively. } \\
\text { Resurfaced group: } 1 \% \text { had re-operations for compli- } \\
\text { cations of the resurfacing during the second } 5 \text { years. } \\
\text { Findings were independent of trochlear design. } \\
\text { Un-resurfaced total costs at } 10 \text { years: } £ 8889 \\
\text { Patella resurfacing total costs at } 10 \text { years } £ 8,785 \\
\text { Patella resurfacing saves } £ 104 \text { per person. } \\
\text { Un-resurfaced vs resurfaced patellae QALY: } 5.110 \text { vs } \\
5.297 \\
\text { Patella resurfacing results in trend towards } 0.187 \\
\text { increase in QALYs. }\end{array}$ & $\begin{array}{l}\text { Patella resurfacing may be } \\
\text { more cost-effective. }\end{array}$ \\
\hline
\end{tabular}


who may be unsuitable for primary resurfacing in the decision-making process (for example, those with insufficient bone stock).

\section{Key points}

Overall, patella resurfacing may be more cost-effective, resulting in an increase in QALYs gained. This is consistent with the 2020 NICE recommendations for patella resurfacing $[12,22,23]$.

\section{The influence of implant design on outcomes}

TKA component design may influence knee biomechanics and performance. Early designs gave little consideration to the patellofemoral joint and resulted in complications in up to $50 \%$ of cases [29].

\section{Femoral component}

The high rates of patellofemoral complications have led to the development of patella-friendly components. Those with a deeper trochlea groove and larger lateral flange have been shown to improve patella tracking and stability [30, 31]. However, a study of 10,157 TKAs (9530 PPR, 627 PPNR) found no significant difference in revision rates between various patella-friendly and earlier designs [15].

\section{Patella component}

Patella components can be cemented or non-cemented, inlayed or onlayed, metal-backed or all-polyethylene, and are available in various morphologies. Inlay and onlay patellae have shown similar kinematic profiles in laboratory studies, but the relative ease of application and potential to medialise to improve tracking has led to a preference for onlay $[32,33]$. Registry data shows that onlay cemented patella resurfacings are the most commonly used in the UK and are associated with good outcomes [2]. More important than the prosthesis is the positioning, as asymmetric resection may lead to patella tilt $[33,34]$, and failure to medialise can result in increased shear forces [35].

\section{Prosthesis constraint}

Registry data suggests that rates of SPR are higher in posterior-stabilised (PS) TKA. Analysis of the New Zealand Joint Registry found PS-TKAs were at increased risk of undergoing SPR with an odds ratio of 1.9 (95\% CI 1.34-2.69, $p<0.0001$ ) [36]. This is consistent with previous literature [37] and data from the UK NJR which show higher rates of revision for implants with a PS design [2]. The revision rate of the PFC Sigma bicondylar knee cemented PS knee at 10 years was 2.6\% (2.36$2.87)$ and $4.37 \%$ (3.99-4.78) for PPR and PPNR respectively. Whereas the Attune PS[Fem] fixed bearing (FB) [tib] revision rate was $2.93 \%$ vs $3.85 \%$ for PPR and
PPNR at 10 years, respectively. PS Gen II Oxinium [Fem] Gen II [tib] $7.09 \%$ vs $15.2 \%$ at 13 years. PS Gen II [fem and tib] $4.38 \%$ vs $4.47 \%$ at 13 years (interestingly at 15 years the PPNR group increases to $6.86 \%$ but there is no comparative data for the PPR group). In contrast, the rates of cumulative revision are consistent between resurfaced and non-resurfaced TKAs for unconstrained TKAs where the cruciate ligaments are retained (CR).

The mechanism for this discrepancy is not clear: it has been hypothesised that the use of PS-TKA is indicated in more complex cases and pre-existing ligamentous deficiency, therefore biasing outcomes [36].

\section{Key points}

Patella-friendly prostheses are yet to eradicate anterior knee pain. Onlay cemented patella resurfacing is the most popular design and is associated with improved survivorship. Registry data suggest PS TKA may be an additional indication for resurfacing.

\section{Risks associated with primary patella resurfacing}

Proponents of primary patella non-resurfacing (PPNR) may quote risks of complications related to patella resurfacing such as patella fracture, mal-positioning, maltracking and tendon rupture [38].

\section{Patella fracture}

Patella fracture is the second most common type of periprosthetic fracture after supracondylar fractures [39]. Patella fractures can be challenging to manage and a systematic review found that $69 \%$ of patella fractures are managed conservatively [40]. They can occur in resurfaced and non-resurfaced patellae, although the majority (99\%) are associated with resurfacing [40, 41]. The mechanism of injury is most commonly atraumatic or low energy trauma, and the majority are asymptomatic [40]. In addition to the patella resurfacing, risk factors for fracture can be grouped into patient factors (e.g. osteoporosis, male, inflammatory arthropathy, obesity), implant design factors (e.g. cementless implants, large central peg) and operative factors (e.g. patella devascularisation, inappropriate use of patella clamp, component malpositioning or excessive resection) [38]. A systematic review of 23 studies estimated the mean incidence of patella fracture after TKA to be $1.19 \%$ (range 0.15 and 12\%) [40]. However, the article reporting the highest rate of fracture was a series of 41 patients that underwent isolated patella component revision, a major risk factor for patella fracture [42]. Whereas the incidence of patella fracture in non-resurfaced knees was $0.05 \%$ [43]. In a retrospective review of 12,464 TKAs between 1985 and 1998 at an American institution, the patella fracture rate was $0.68 \%$ [44]. All fractures were associated with patella resurfacing, but the prevalence of PPR within the cohort 
was not reported. The latest NJR report calculates 0.17 of revision TKAs were performed for peri-prosthetic fractures per 1000 prosthesis-years [2] although there is no specific estimate for patella fractures. In any case, the absolute incidence of patella fracture was low.

\section{Aseptic loosening}

Historically, rates varied from 0.6 to $4.8 \%$, but aseptic loosening has decreased since metal-backed patella resurfacings, which had high rates of failure, have been abandoned [45]. Risk factors for aseptic loosening include obesity, lateral release and joint elevation. Although aseptic loosening is a predominant mechanism of TKA failure overall [46], cases of patella loosening are rare. In a series of 310 TKAs with PPR performed between 2001 and 2008 and followed up for a mean of 96 (58-144) months, there was one $(0.3 \%)$ case of aseptic loosening that presented at 62 months [45]. The presence of a patella resurfacing creates another source of polyethylene wear which could contribute to aseptic loosening of the tibial or femoral components, but the latest NJR report shows higher rates of revision for aseptic loosening in cemented TKA (both CR and PS) when the patella was not resurfaced [2].

\section{Avascular necrosis}

Extensive lateral release is often attributed as the mechanism for patella devascularisation and has been shown to increase the risk of aseptic loosening and patella fracture 3.8 -fold and 2.7-fold, respectively [47]. In a retrospective study of 844 primary TKAs that underwent revision, avascular necrosis of the patella was the reported indication in only $2(0.2 \%)$ cases [46].

\section{Patella clunk syndrome}

Patella clunk syndrome has been described following both PPR and PPNR [48]. The estimated incidence is 0$20 \%$ depending on the design of the prosthetic patella [49]. In a systematic review investigating the aetiology of patella clunk syndrome, 3 of 30 studies identified PPR as a significant risk factor, and 1 of 30 suggested that PPR was a non-significant risk factor, with the remaining making no comment [49]. A recent randomised controlled study investigating patella crepitus, a pathology related to patella clunk, in resurfaced and nonresurfaced posterior-stabilised TKAs found the incidence was lower in the PPR group (7.3\% vs $23.1 \%$ ) [50]. Avoiding known risk factors for patella clunk such as smaller patella button size and decreased composite patella thickness [51] may reduce the incidence further.

\section{Overstuffing}

Overstuffing of the patellofemoral compartment is influenced by the femoral component size and position as well as patella thickness. Overstuffing risks higher joint reaction forces, patella fracture, reduced range of motion and anterior knee pain; understuffing risks a reduction in knee extension strength, extensor lag and instability [52]. Despite these theoretical risks, recent clinical studies correlating radiographic appearance and clinical outcomes have been mixed [53-55].

\section{Instability}

Patient, implant and operative factors all contribute to patella instability [38]. Specific considerations when resurfacing the patella are to medialise the patella button to mitigate the need for lateral retinacular release [56], but not so excessively as to cause lateral patella tilt. Most cases of instability are related to internal rotation of the femoral or tibial component therefore not limited to PPR $[57,58]$. Historic incidence of patella instability is between 1 and 20\% [59]; however, in a retrospective analysis of 255 posterior stabilised-TKAs with PPR, there were no cases of patella instability and 5 cases of mild lateral patella tilt [60].

\section{Extensor mechanism disruption}

Extensor mechanism failure via damage to the quadriceps tendon, patella or patella tendon is a potentially catastrophic complication with high morbidity [61]. Quadriceps tendon injury is rare, occurring in $0.1 \%$ of TKAs [61]. Patella tendon injury is reputedly the most difficult extensor mechanism injury to treat, with complication rates of $63 \%$ [62] and an incidence of $0.17 \%$ [63]. Patella fracture is the most common extensor mechanism injury after TKA and 99\% are associated with PPR but the majority do not result in a disruption [44] (see above evidence for patella fractures). Risk factors, both intra- and post-operatively, are numerous and are usually linked to direct trauma at the time of surgery or suboptimal implant positioning leading to increased stress when ambulating. Extensor mechanism failure is rare, accounting for $1.2 \%$ of revision TKAs [46]. In a series of 860 PPR TKAs, $1.3 \%$ sustained patella fractures and $0.47 \%$ sustained patella tendon rupture, although the authors highlighted that most fractures were secondary to trauma and patella tendon ruptures followed previous surgery such as valgus osteotomy [64].

\section{Key points}

Despite the potential pitfalls of patella resurfacing described in the literature, the absolute risks are low and continue to decrease with improving implant designs [65]. With diligent patient selection, pre-operative planning and attention to intraoperative technique the risks can be reduced further [52] (Table 3). 
Table 3 Techniques and considerations to mitigate the risk of complications following PPR

\begin{tabular}{ll}
\hline Complication & Consideration/technique \\
\hline Patella fracture & Using all-polyethylene patella button \\
& Avoiding button with large central peg \\
& Avoiding excessive patella resection \\
Patella avascular necrosis & Avoiding excessive lateral retinacular release \\
& Avoiding excessive patella reaming \\
Patella clunk & Femoral component: low intercondylar box ratio \\
& Avoiding significant changes in joint line height, reduced patella thickness, using a small patella button \\
& Maintaining posterior condylar offset \\
Under/overstuffing & Restoring native patella thickness \\
& Using appropriate size femoral component without anteriorisation \\
Patella instability & Using femoral component with extended and deep trochlea groove \\
& Attention to internal rotation of femoral component \\
& Tibial component external rotation and centralisation \\
& Medialising and superiorisation of patella button \\
Performing a lateral patella facetectomy if necessary & Avoiding aggressive eversion of patella \\
Extensor mechanism disruption & Avoid change of joint line height \\
\hline
\end{tabular}

\section{The fate of non-resurfaced patellae}

Surgeons opting not to resurface the patella may be reassured by the appearance of healthy patella cartilage intra-operatively. However, an RCT of 125 TKAs assessed the patella cartilage on a scale of 0 (pristine cartilage) to 12 (eburnated) at time of surgery and although lower scores correlated with better outcomes, there were cases of high scores with good outcomes and vice versa, highlighting the unpredictable nature of selective resurfacing [11]. Furthermore, those that returned for SPR were evenly distributed between high and low patella scores.

\section{Cellular changes of patella cartilage when everted during surgery}

During TKA, the patella is often everted to gain access. In a rabbit model, exposure of hyaline cartilage to air for more than 60 min caused full thickness chondrocyte necrosis, although, when reviewed at 3 weeks, there was no evidence of necrosis, hence chondrocyte necrosis may be potentially reversible [66]. Laminar flow was associated with increased rate of chondrocyte necrosis versus static air, and although rehydration macroscopically restores cartilage, there was no reversal of chondrocyte necrosis. These deleterious effects were prevented using a saline soaked gauze [67].

\section{Interaction of metal-on-cartilage for PPNR}

Cartilage is damaged following interaction with metal implants [68], with decreased cell viability, extracellular matrix disruption and increased wear when compared to cartilage-on-cartilage interaction [69]. This unfavourable interaction may partially explain the higher rates of anterior knee pain seen with PPNR. Over time, the native patella may become eroded. In a RCT involving 125
TKAs, all 6 non-resurfaced knees that returned for SPR had developed radiological evidence of wear and half were found to have bone loss intra-operatively [11].

\section{Key points}

The fate of the non-resurfaced patella is not evidenced but is unlikely to flourish in a prosthetic environment after surgery.

\section{Conclusion}

The authors suggest routine PPR in line with NICE guidelines, based on evidence of at least equivocal clinical outcomes, lower re-operation rates, economic viability and low risk of complications with modern implants and sound surgical technique. Adequately powered randomised controlled trials with appropriate outcome measures and sufficiently long follow-up are needed to give a definitive answer to this clinically relevant issue.

\section{Abbreviations \\ AJRR: American Joint Replacement Registry; AKP: Anterior knee pain; Cl: Confidence intervals; CR: Cruciate retaining; fem: Femoral component; FB: Fixed bearing; KAT: Knee Arthroplasty Trial; KSS: Knee Society Score; NICE: National Institute for Health and Clinical Excellence; PROM: Patient Reported Outcome Measure; PFJ: Patellofemoral joint; PPNR: Primary patella non-resurfacing; PPR: Primary patella resurfacing; PFC: Press-fit condylar; PS: Posterior-stabilised; QALY: Quality adjusted life years; RCT: Randomised controlled trial; SPR: Secondary patella resurfacing; TKA: Total knee arthroplasty; Tib: Tibial component; UK NJR: United Kingdom, National Joint Registry}

\section{Acknowledgements}

Not applicable.

\section{Authors' contributions}

D. F. Kader designed the article layout, drafted, edited and approved the manuscript. TM Parsons drafted, edited and approved the manuscirpt. T AlJabri: Drafted, edited and approved the manuscript. ND Clement and N Maffuli edited and approved the manuscript. All authors read and approved the final manuscript. 


\section{Funding}

The authors did not receive any funding for this article.

\section{Ethics approval and consent to participate}

This was not required for this article.

\section{Consent for publication}

Not applicable.

\section{Competing interests}

The authors declare that they do not have any competing interests.

\section{Author details}

'South West London Elective Orthopaedic Centre, Denbies Wing, Epsom General Hospital, Surrey KT18 7EG, UK. ${ }^{2}$ Royal United Hospital Bath, Combe Park, Bath, Avon BA1 3NG, UK. ${ }^{3}$ Department of Surgery and Cancer, Imperial College London, London SW7 2AZ, England. ${ }^{4}$ Department of Orthopaedics, Royal Infirmary of Edinburgh, Little France, Edinburgh EH16 4SA, UK. ${ }^{5}$ Department of Medicine, Surgery and Dentistry, University of Salerno, Via S. Allende, 84081 Baronissi, SA, Italy. ${ }^{6}$ Queen Mary University of London, Barts and the London School of Medicine and Dentistry, Centre for Sports and Exercise Medicine, Mile End Hospital, 275 Bancroft Road, London E1 4DG, England. ${ }^{7}$ School of Pharmacy and Bioengineering, Keele University School of Medicine, Stoke on Trent ST5 5BG, UK. ${ }^{8}$ University of Kurdistan Hewler, Erbil, Iraq

Received: 19 January 2021 Accepted: 10 February 2021

Published online: 11 March 2021

\section{References}

1. Academy of Orthopaedic Surgeons A. American Joint Replacement Registry | 7th Annual Report. 2020. Available from: http://connect.ajrr.net/2020-ajrr-a nnual-report

2. Ireland NJR for EW and N. National Joint Registry | 17th Annual Report. 2020 [cited 2020 Dec 11]. Available from: https://reports.njrcentre.org.uk/Portals/ 0/PDFdownloads/NJR 17th Annual Report 2020.pdf

3. Ali A, Lindstrand A, Nilsdotter A, Sundberg M. Similar patient-reported outcomes and performance after total knee arthroplasty with or without patellar resurfacing. Acta Orthop. 2016;87(3):274-9 [cited 2020 June 9]; Available from: http://www.ncbi.nlm.nih.gov/pubmed/27212102.

4. Parvizi J, Rapuri VR, Saleh KJ, Kuskowski MA, Sharkey PF, Mont MA. Failure to resurface the patella during total knee arthroplasty may result in more knee pain and secondary surgery. Clin Orthop Relat Res. 2005;438 [cited 2020 Dec 5]. Available from: https://pubmed.ncbi.nlm.nih.gov/16131890/.

5. Li S, Chen Y, Su W, Zhao J, He S, Luo X. Systematic review of patellar resurfacing in total knee arthroplasty. Int Orthop 2011;35:305-316. [cited 2020 Dec 14]. Available from: https://doi.org/10.1007/s00264-010-1109-2

6. Chen K, Li G, Fu D, Yuan C, Zhang Q, Cai Z. Patellar resurfacing versus nonresurfacing in total knee arthroplasty: a meta-analysis of randomised controlled trials. Int Orthop. 2013;37(6):1075-83 [cited 2018 Nov 15]. Available from: http://www.ncbi.nlm.nih.gov/pubmed/23529719.

7. He JY, Jiang LS, Dai LY. Is patellar resurfacing superior than nonresurfacing in total knee arthroplasty? A meta-analysis of randomized trials. Knee. 2011; 18:137-44.

8. Fu Y, Wang G, Fu Q. Patellar resurfacing in total knee arthroplasty for osteoarthritis: a meta-analysis. Knee Surg Sport Traumatol Arthrosc 2011 19(9):1460-1466. [cited 2020 Dec 14]. Available from: https://doi.org/10.1 007/s00167-010-1365-0

9. Arirachakaran A, Sangkaew C, Kongtharvonskul J. Patellofemoral resurfacing and patellar denervation in primary total knee arthroplasty. Knee Surg Sports Traumatol Arthrosc 2015;23:1770-1781. [cited 2020 Dec 14]. Available from: https://doi.org/10.1007/s00167-014-3311-z

10. Teel AJ, Esposito JG, Lanting BA, Howard JL, Schemitsch EH. Patellar Resurfacing in primary total knee arthroplasty: a meta-analysis of randomized controlled trials. J Arthroplasty 2019;34(12):3124-3132. [cited 2020 Dec 6]. Available from: https://pubmed.ncbi.nlm.nih.gov/31427130/

11. Newman JH, Ackroyd CE, Shah NA, Karachalios T. Should the patella be resurfaced during total knee replacement? Knee. 2000;7(1):17-23 [cited 2020 Dec 23]. Available from: https://linkinghub.elsevier.com/retrieve/pii/S096801 6099000332
12. Evidence review for patella resurfacing: Joint replacement (primary): hip, knee and shoulder: Evidence review L. 2020 [cited 2020 Dec 10]. Available from: http://www.ncbi.nlm.nih.gov/pubmed/32881465

13. Nizard RS, Biau D, Porcher R, Ravaud P, Bizot P, Hannouche D, et al. A metaanalysis of patellar replacement in total knee arthroplasty. Clin Orthop Relat Res. 2005;NA(432):196-203 [cited 2020 Dec 29]. Available from: http://journa Is.Iww.com/00003086-200503000-00026.

14. Pilling RWD, Moulder E, Allgar V, Messner J, Sun Z, Mohsen A. Patellar resurfacing in primary total knee replacement: a meta-analysis. J Bone Joint Surg Am 2012;94(24):2270-2278. [cited 2019 Oct 24]. Available from: http:// www.ncbi.nlm.nih.gov/pubmed/23318618

15. Johnson TC, Tatman PJ, Mehle S, Gioe TJ. Revision surgery for patellofemoral problems: should we always resurface? Clin Orthop Relat Res 2012;470(1):211-219. [cited 2018 Nov 18]. Available from: https://doi.org/1 $0.1007 / \mathrm{s} 11999-011-2036-2$

16. Pakos EE, Ntzani EE, Trikalinos TA. Patellar resurfacing in total knee arthroplasty: a meta-analysis. J Bone Jt Surg. 2005:87(7):1438-45 [cited 2020 Dec 13]. Available from: https://pubmed.ncbi.nlm.nih.gov/15995109/.

17. Fraser JF, Spangehl MJ. International Rates of Patellar Resurfacing in Primary Total Knee Arthroplasty, 2004-2014. J Arthroplasty. 2017;32(1):83-6 [cited 2019 Feb 6]. Available from: https://inkinghub.elsevier.com/retrieve/pii/ S0883540316302753.

18. Thomas C, Patel V, Mallick E, Esler C, Ashford RU. The outcome of secondary resurfacing of the patella following total knee arthroplasty: Results from the Trent and Wales Arthroplasty Register. Knee. 2018;25(1):146-52 [cited 2019 Feb 20]. Available from: https://linkinghub.elsevier.com/retrieve/pii/S096801 6017302934.

19. Parvizi J, Mortazavi SMJ, Devulapalli C, Hozack WJ, Sharkey PF, Rothman RH. Secondary Resurfacing of the Patella After Primary Total Knee Arthroplasty. Does the Anterior Knee Pain Resolve? J Arthroplasty. 2012;27(1):21-6.

20. Wood DJ, Smith AJ, Collopy D, White B, Brankov B, Bulsara MK. Patellar resurfacing in total knee arthroplasty: a prospective, randomized trial. J Bone Jt Surg. 2002;84(2) [cited 2020 Dec 29]. Available from: https://pubmed.ncbi. nlm.nih.gov/11861723/.

21. Waters TS, Bentley G. Patellar resurfacing in total knee arthroplasty. A prospective, randomized study. J Bone Jt Surg. 2003;85(2):212-7 [cited 2020 Dec 29]. Available from: https://pubmed.ncbi.nlm.nih.gov/12571296/.

22. Murray DW, MacLennan GS, Breeman S, Dakin HA, Johnston L, Campbell MK, et al. A randomised controlled trial of the clinical effectiveness and cost-effectiveness of different knee prostheses: The Knee Arthroplasty Trial (KAT). Health Technol Assess. 2014;18(19):1-235.

23. Weeks CA, Marsh JD, MacDonald SJ, Graves S, Vasarhelyi EM. Patellar resurfacing in total knee arthroplasty: a cost-effectiveness analysis. J Arthroplasty. 2018;33(11):3412-5 [cited 2020 Dec 6]. Available from: https:// pubmed.ncbi.nlm.nih.gov/30122432/.

24. Thomas C, Patel V, Mallick E, Esler C, Ashford RU. The outcome of secondary resurfacing of the patella following total knee arthroplasty: Results from the Trent and Wales Arthroplasty Register. Knee. 2018;25(1):146-52 [cited 2018 Nov 27]. Available from: http://www.ncbi.nlm.nih.gov/pubmed/29366665.

25. Ikejiani $C E$, Leighton $\mathrm{R}$, Petrie DP. Comparison of patellar resurfacing versus nonresurfacing in total knee arthroplasty. Can J Surg. 2000;43(1):35-8 [cited 2020 Dec 11]. Available from: /pmc/articles/PMC3788924/?report=abstract.

26. Meneghini RM. Should the patella be resurfaced in primary total knee arthroplasty? An evidence-based analysis. J Arthroplasty. 2008;23(7 SUPPL):11-4 [cited 2020 Dec 11]. Available from: https://pubmed.ncbi.nlm.nih.gov/18701250/.

27. Brick GW, Scott RD. The patellofemoral component of total knee arthroplasty. Clin Orthop Relat Res. 1988;231:163-78.

28. Kuo AW, Chen DB, Wood J, MacDessi SJ. Modern total knee arthroplasty designs do not reliably replicate anterior femoral morphology. Knee Surg Sport Traumatol Arthrosc. 2020;28(9):2808-15.

29. Healy WL, Wasilewski SA, Takei R, Oberlander M. Patellofemoral complications following total knee arthroplasty. Correlation with implan design and patient risk factors. J Arthroplasty. 1995;10(2):197-201 [cited 2020 Dec 6]. Available from: https://pubmed.ncbi.nlm.nih.gov/7798101/.

30. Yoshii I, Whiteside LA, Anouchi YS. The effect of patellar button placement and femoral component design on patellar tracking in total knee arthroplasty. Clin Orthop Relat Res. 1992;275:211-9.

31. Engh GA, Dwyer KA, Hanes CK. Polyethylene wear of metal-backed tibial components in total and unicompartmental knee prostheses. J Bone Jt Surg. 1992;74(1):9-17 [cited 2020 Dec 14]. Available from: https://pubmed. ncbi.nlm.nih.gov/1732274/. 
32. Ezzet KA, Hershey AL, D'Lima DD, Irby SE, Kaufman KR, Colwell CW. Patellar tracking in total knee arthroplasty: Inset versus onset design. J Arthroplasty. 2001;16(7):838-43 [cited 2020 Dec 14]. Available from: https://pubmed.ncbi. nlm.nih.gov/11607898/.

33. Anglin C, Brimacombe JM, Hodgson AJ, Masri BA, Greidanus NV, Tonetti J, et al. Determinants of patellar tracking in total knee arthroplasty. Clin Biomech. 2008;23(7):900-10.

34. Pagnano MW, Trousdale RT. Asymmetric patella resurfacing in total knee arthroplasty. Am J Knee Surg. 2000;13(4):228-33.

35. D'Lima DD, Chen PC, Kester MA, Colwell CW. Impact of patellofemoral design on patellofemoral forces and polyethylene stresses. J Bone Joint Surg. 2003;85:85-93 [cited 2020 Dec 14]. Available from: https://pubmed. ncbi.nlm.nih.gov/14652397/.

36. Maney AJ, Frampton CM, Young SW. Age and prosthetic design as risk factors for secondary patella resurfacing. J Arthroplasty. 2020;35(6):1563-8 [cited 2020 Dec 15]. Available from: https://pubmed.ncbi.nlm.nih.gov/3203 7214/.

37. Elson DW, Brenkel IJ. Predicting pain after total knee arthroplasty. J Arthroplasty. 2006:21(7):1047-53.

38. Assiotis A, To K, Morgan-Jones R, Pengas IP, Khan W. Patellar complications following total knee arthroplasty: a review of the current literature. Eur J Orthop Surg Traumatol. 2019;29:1605-15 [cited 2020 Dec 6]. Available from: https://pubmed.ncbi.nlm.nih.gov/31302764/.

39. Agarwal S, Sharma RK, Jain JK. Periprosthetic fractures after total knee arthroplasty. J Orthop Surg. 2014;22(1):24-9.

40. Chalidis BE, Tsiridis E, Tragas AA, Stavrou Z, Giannoudis PV. Management of periprosthetic patellar fractures. A systematic review of literature. Injury. 2007;38(6):714-24 [cited 2020 Dec 14]. Available from: https://pubmed.ncbi. nlm.nih.gov/17477924/.

41. Tharani R, Nakasone C, Vince KG. Periprosthetic fractures after total knee arthroplasty. In: Journal of Arthroplasty. J Arthroplasty. 2005:27-32 [cited 2020 Dec 10]. Available from: https://pubmed.ncbi.nlm.nih.gov/15991125/.

42. Berry DJ, Rand JA. Isolated patellar component revision of total knee arthroplasty. Clin Orthop Relat Res. 1993;286:110-5.

43. Goldberg VM, Figgie HE 3rd, Inglis AE, Figgie MP, Sobel M, Kelly M, et al. Patellar fracture type and prognosis in condylar total knee arthroplasty. Clin Orthop Relat Res. 1988;236:115-22.

44. Ortiguera CJ, Berry DJ. Patellar fracture after total knee arthroplasty. J Bone Jt Surg. 2002;84(4):532-40 [cited 2020 Dec 12]. Available from: https:// pubmed.ncbi.nlm.nih.gov/11940611/.

45. Schiavone Panni A, Cerciello S, Del Regno C, Felici A, Vasso M. Patellar resurfacing complications in total knee arthroplasty. Int Orthop. 2014;38: 313-7 [cited 2020 Dec 10]. Available from: https://pubmed.ncbi.nlm.nih. gov/24363045/.

46. Schroer WC, Berend KR, Lombardi AV, Barnes CL, Bolognesi MP, Berend ME, et al. Why are total knees failing today? Etiology of total knee revision in 2010 and 2011. J Arthroplasty. 2013;28(8 SUPPL):116-9 [cited 2020 Dec 12] Available from: https://pubmed.ncbi.nlm.nih.gov/23954423/.

47. Meding JB, Fish MD, Berend ME, Ritter MA, Keating EM. Predicting patellar failure after total knee arthroplasty. Clin Orthop Relat Res. 2008:2769-74 [cited 2020 Dec 12]. Available from: https://pubmed.ncbi.n/m.nih.gov/1 $8712456 /$.

48. Shoji H, Shimozaki E. Patellar clunk syndrome in total knee arthroplasty without patellar resurfacing. J Arthroplasty. 1996;11(2):198-201 [cited 2020 Dec 12]. Available from: https://pubmed.ncbi.nlm.nih.gov/8648316/.

49. Sequeira SB, Scott J, Novicoff W, Cui Q. Systematic review of the etiology behind patellar clunk syndrome. World J Orthop. 2020;11(3):184-96 [cited 2020 Dec 6]. Available from: /pmc/articles/PMC7138860/?report=abstract.

50. Thiengwittayaporn S, Srungboonmee K, Chiamtrakool B. Resurfacing in a posterior-stabilized total knee arthroplasty reduces patellar crepitus complication: a randomized, controlled trial. J Arthroplasty. 2019;34(9):1969_ 74 [cited 2020 Dec 15]. Available from: https://pubmed.ncbi.nlm.nih. gov/31126775/.

51. Dennis DA, Kim RH, Johnson DR, Springer BD, Fehring TK, Sharma A. The John Insall Award: control-matched evaluation of painful patellar Crepitus after total knee arthroplasty. Clin Orthop Relat Res. 2011;469(1):10-7.

52. Matz J, Lanting BA, Howard JL. Understanding the patellofemoral joint in total knee arthroplasty. Can J Surg. 2019;62:57-65 [cited 2020 Dec 12]. Available from: https://pubmed.ncbi.nlm.nih.gov/30693747/.

53. Beldman M, Breugem SJM, van Jonbergen HPW. Overstuffing in total knee replacement: no effect on clinical outcomes or anterior knee pain. Int
Orthop. 2015;39(5):887-91 [cited 2020 Dec 12]. Available from: https:// pubmed.ncbi.nlm.nih.gov/25307257/.

54. Pierson $J$ L, Ritter MA, Keating EM, Faris PM, Meding JB, Berend ME, et al. The effect of stuffing the patellofemoral compartment on the outcome of total knee arthroplasty. J Bone Joint Surg. 2007;89:2195-203 [cited 2020 Dec 12]. Available from: https://pubmed.ncbi.nlm.nih.gov/17908896/.

55. Scott CE, Clement ND, Yapp LZ, Mac Donald DJ, Patton JT, Burnett R. Association between femoral component sagittal positioning and anterior knee pain in total knee arthroplasty: a 10-year case-control follow-up study of a cruciate-retaining single-radius design. J Bone Jt Surg. 2019;101(17): 1575-85 [cited 2020 Dec 16]. Available from: https://pubmed.ncbi.nlm.nih gov/31483401/.

56. Eisenhuth SA, Saleh KJ, Cui Q, Clark CR, Brown TE. Patellofemoral instability after total knee arthroplasty. Clin Orthop Relat Res. 2006:149-60 [cited 2020 Dec 12]. Available from: https://pubmed.ncbi.nlm.nih.gov/16672884/.

57. Putman S, Boureau F, Girard J, Migaud H, Pasquier G. Patellar complications after total knee arthroplasty. Orthop Traumatol. 2019;105:S43-51 [cited 2020 Dec 12]. Available from: https://pubmed.ncbi.nlm.nih.gov/29990602/.

58. Berger RA, Crossett LS, Jacobs JJ, Rubash HE. Malrotation causing patellofemoral complications after total knee arthroplasty. Clin Orthop Relat Res. 1998:144-53 [cited 2020 Dec 29]. Available from: https://pubmed.ncbi. nlm.nih.gov/9917679/.

59. Merkow RL, Soudry M, Insall JN. Patellar dislocation following total knee replacement. J Bone Joint Surg Am. 1985;67(9):1321-7.

60. Lachiewicz PF, Soileau ES. Patella maltracking in posterior-stabilized total knee arthroplasty. Clin Orthop Relat Res. 2006:155-8 [cited 2020 Dec 12]. Available from: https://pubmed.ncbi.nlm.nih.gov/16936588/.

61. Dobbs RE, Hanssen AD, Lewallen DG, Pagnano MW. Quadriceps tendon rupture after total knee arthroplasty: Prevalence, complications, and outcomes. J Bone Jt Surg. 2005;87(1):37-45 [cited 2020 Dec 12]. Available from: https://pubmed.ncbi.nlm.nih.gov/15634812/.

62. Vajapey SP, Blackwell RE, Maki AJ, Miller TL. Treatment of extensor tendon disruption after total knee arthroplasty: a systematic review. J Arthroplasty. 2019;34:1279-86 [cited 2020 Dec 16]. Available from: https://pubmed.ncbi. nlm.nih.gov/30902501/.

63. Rand JA, Morrey BF, Bryan RS. Patellar tendon rupture after total knee arthroplasty. Clin Orthop Relat Res. 1989;244:233-8 [cited 2020 Dec 16]. Available from: https://pubmed.ncbi.nlm.nih.gov/2743664/.

64. Silvestre A, Lopez R, Almeida F, Renovell P, Arguelles F, Vaamonde O. Extensor Mechanism Complications After Patellar Resurfacing in Knee Replacement - Can They Justify Non-Patellar Resurfacing? Arthroplasty. 2013; [cited 2020 Dec 16]. Available from: https://www.intechopen.com/ books/arthroplasty-update/extensor-mechanism-complications-after-patellarresurfacing-in-knee-replacement-can-they-justify-non.

65. Park BK, Paprosky WG. Patellar resurfacing in total knee arthroplasty. Semin Arthroplasty. 2015;26(4):232-5.

66. Han CD, Kang HJ. Changes in the hyaline articular cartilage after air exposure. Yonsei Med J. 1990;31(1):53-9 [cited 2020 Dec 6]. Available from: https://pubmed.ncbi.nlm.nih.gov/1693254/.

67. Paterson SI, Amin AK, Hall AC. Airflow accelerates bovine and human articular cartilage drying and chondrocyte death. Osteoarthr Cartil. 2015; 23(2):257-65 [cited 2020 Dec 6]. Available from: https://pubmed.ncbi.nlm. nih.gov/25463263/.

68. Oungoulian SR, Durney KM, Jones BK, Ahmad CS, Hung CT, Ateshian GA. Wear and damage of articular cartilage with friction against orthopedic implant materials. J Biomech. 2015;48(10):1957-64 [cited 2020 Dec 6]. Available from: /pmc/articles/PMC4492870/?report=abstract.

69. Trevino RL, Stoia J, Laurent MP, Pacione CA, Chubinskaya S, Wimmer MA. Establishing a live cartilage-on-cartilage interface for tribological testing. Biotribology. 2017;9:1-11 [cited 2020 Dec 6]. Available from: /pmc/articles/ PMC5726278/?report=abstract.

\section{Publisher's Note}

Springer Nature remains neutral with regard to jurisdictional claims in published maps and institutional affiliations. 